\title{
Role of oxidative stress in liver toxicity induced by nickel oxide nanoparticles in rats
}

\author{
SHU YU*, FANGFANG LIU*, CHEN WANG, JINGYI ZHANG, AN ZHU, LINGYUE ZOU, \\ AIJIE HAN, JIN LI, XUHONG CHANG and YINGBIAO SUN
}

Department of Toxicology, School of Public Health, Lanzhou University, Lanzhou, Gansu 730000, P.R. China

Received August 15, 2016; Accepted May 12, 2017

DOI: $10.3892 / \mathrm{mmr} .2017 .8226$

\begin{abstract}
The aim of the present study was to explore the role of oxidative stress in liver toxicity induced by nickel oxide nanoparticles (nano-NiO) in rats. Male Wistar rats received saline (control), nano-NiO [0.015, 0.06 or $0.24 \mathrm{mg} / \mathrm{kg}$ body weight (b.w.)] or micro- $\mathrm{NiO}(0.24 \mathrm{mg} / \mathrm{kg}$ b.w.) by intratracheal instilling twice a week for 6 weeks. Liver tissues were then collected and examined for biomarkers of nitrative and oxidative stress, as well as mRNA expression of heme oxygenase (HO)-1 and metallothionein (MT)-1. The results demonstrated that the $\mathrm{NiO}$ exposure groups had increased liver wet weight and coefficient to body weight, as well as liver pathological changes, evidenced as cellular edema, hepatic sinus disappearance and binucleated hepatocytes. The activities of total nitric oxide synthase and inducible nitric oxide synthase, and the nitric oxide content, were increased in the $0.24 \mathrm{mg} / \mathrm{kg}$ nano-NiO group compared with the control group. The MT-1 mRNA expression levels were downregulated, while $\mathrm{HO}-1$ mRNA was upregulated in the $0.24 \mathrm{mg} / \mathrm{kg}$ nano-NiO exposure group compared with the control group. In addition, abnormal changes of hydroxyl radical, lipid peroxidation, catalase, glutathione peroxidase, total superoxide dismutase and total antioxidative capacity were observed in the liver tissues of the $0.24 \mathrm{mg} / \mathrm{kg}$ nano-NiO exposure group, compared with the control group. The present results therefore indicated that nano-NiO-induced liver toxicity may be associated with nitrative and oxidative stress in rats.
\end{abstract}

Correspondence to: Professor Yingbiao Sun or Dr Xuhong Chang, Department of Toxicology, School of Public Health, Lanzhou University, 199 Donggang West Road, Lanzhou, Gansu 730000, P.R. China

E-mail: sunyb@lzu.edu.cn

E-mail: changxh@1zu.edu.cn

*Contributed equally

Key words: nanoparticle, nickel oxide, liver toxicity, oxidative stress

\section{Introduction}

Nanotechnology, the branch of technology that develops novel materials at size of $<100 \mathrm{~nm}$, has become one of the most promising areas of engineering research (1). Manufactured metal oxide nanomaterials are among the most widely used types of engineered nanomaterials (2). Nickel oxide nanoparticles (nano-NiO) are drawing significant research interest due to their multiple applications, including as sensors, battery electrodes, catalysts and cosmetics $(3,4)$. Because of the extensive potential of nano-NiO particles and their emerging applications, it is essential to understand their implications in human safety (5).

In recent years, toxicity and risk assessments of nano-NiO have caught much attention. Single intratracheal instillation of nano-NiO in rats induces oxidative stress, inflammatory response, collagen deposition, and apoptosis in lung tissues (6-8). In our previous studies, nano-NiO was demonstrated to result in lung lesions following intratracheal instillation for 6 weeks in rats and to enhance the nitrative stress and inflammatory response (9), an effect that was associated with nuclear factor- $\kappa \mathrm{B}$ activation and $\mathrm{T}$ helper $(\mathrm{Th}) 1 / \mathrm{Th} 2$ cell imbalance (10). Other reports have also demonstrated that nano-NiO induces toxicity in various cell lines, including human bronchial epithelial cells, type II human alveolar epithelial cells, human monocytes and mouse embryonic stem cells (11-14). Suspensions of nano-NiO cause oxidative stress in nauplii at concentrations $0.2-50 \mathrm{mg} / \mathrm{l}$ for 24 and $96 \mathrm{~h}$ (15).

The liver is the main organ where exogenous materials are metabolized and eventually excreted (16). Therefore, liver cells exposed to exogenous materials could result in liver dysfunction, cell injury, and even organ failure. Pari et al (17) reported that nickel induces necrotic and inflammatory response in rat livers by modulating the reactive radicals due to oxidative stress. Nickel results in oxidative stress and inflammatory response in mouse livers, which may be mediated by the toll-like receptor 4/p38/cAMP response element binding protein pathway (18). Nickel sulfate triggers oxidative stress and apoptosis via the c-Jun N-terminal kinase signaling pathway in the liver of Carassius auratus (19). Permenter et al (20) reported that the mechanism of oxidative stress induced by nickel sulfate in a rat liver-derived cell line may be the activation of hypoxia inducible factor-1 $\alpha$ transcription factor. Ahmad et al (21) reported that nickel chloride induces oxidative stress and apoptosis in human liver cells through the mitochondrial pathway. Nickel 
sulfate has also been reported to cause microvesicular steatosis and necrotic hepatocytes in rat livers (22). Sidhu et al (23) reported that the activities of alkaline phosphatase and alanine aminotransferase increased following treatment with nickel sulfate in rat liver tissues.

While nickel and its compounds have been demonstrated by these previous studies to lead to liver lesions, few studies to date have addressed the potential liver toxicity of nano-NiO in animal models. Ahamed et al (24) have demonstrated that nano-NiO results in cytotoxicity via reactive oxygen species (ROS) and enhances apoptosis in human liver cells (HepG2), which may be mediated by the BCL2 associated X/BCL2 pathway (24). Another study has also demonstrated that nickel nanoparticles induce cytotoxicity and oxidative stress in HepG2 cells (25). Magaye et al (26) reported that nickel nanoparticles cause inflammation in the liver of rats, evident by an increase of the liver coefficient in affected animals. Nanoparticles of nickel ferrite induce cytotoxicity and oxidative stress in human liver hepatocellular carcinoma cells in a dose-dependent manner (27). Katsnelson et al (28) reported that nano-NiO administration in rats via intraperitoneal injection leads to nickel deposition, increased numbers of Kupffer cells, and akaryotic and binucleated hepatocytes in the liver tissues.

Further research is required in order to evaluate the safety of nano-NiO in the liver. In addition, the role of oxidative stress in animal liver toxicity induced by nano-NiO exposure remains unclear. In the present study, a rat model was generated to observe the effects of nano-NiO administration by examining various indicators of liver toxicity, including liver weight, liver coefficient to body weight and histopathological examination. Several biomarkers of nitrative and oxidative stress, as well as the mRNA expression of heme oxygenase (HO)-1 and metallothionein (MT)-1 were evaluated in order to explore the potential mechanism of liver toxicity induced by nano-NiO.

\section{Materials and methods}

$\mathrm{NiO}$ particles characterization. $\mathrm{NiO}$ particles with diameters of $20 \mathrm{~nm}$ and $1 \mu \mathrm{m}$ were obtained from ST-nano Science and Technology Co., Ltd. (Shanghai, China). The purities of both particles were detected with inductively coupled plasma mass spectrometry (7500i; Agilent Technologies, Inc., Santa Clara, CA USA). The specific surface area of $\mathrm{NiO}$ particles was measured by the Brunauer Emmett Teller method (3H-2000PS2; Beishide Instrument Technology Co., Ltd, Beijing, China). The crystal structure of $\mathrm{NiO}$ particles were characterized using an X-ray diffractometer (XRF-1800; Shimadzu Corporation, Kyoto, Japan).

$\mathrm{NiO}$ sample preparation. Nano-NiO particles were dispread into physiological saline at gradient concentrations of 0.015 , 0.06 , and $0.24 \mathrm{mg} / \mathrm{ml}$, following sterilization using a high pressure steam autoclave (MLS-3751L; Panasonic Corporation, Osaka, Japan) at $120^{\circ} \mathrm{C}$ for $30 \mathrm{~min}$, as well as concentration of micro-NiO particles at $0.24 \mathrm{mg} / \mathrm{ml}$. Avoiding the agglomeration of $\mathrm{NiO}$ particles, the suspensions were dispersed using an ultrasonic homogenizer (CP750; Cole-Parmer Instrument Co., Ltd., Vernon Hills, IL, USA) at $750 \mathrm{~W}$ for $30 \mathrm{~min}$, then mechanical vibration for $5 \mathrm{~min}$.
Endotoxin assay of $\mathrm{NiO}$ samples. The Limulus Amebocyte Lysate (LAL) assay was performed to identify whether $\mathrm{NiO}$ particles were contaminated by endotoxins using a ToxinSensor Gel Clot endotoxin assay kit (GenScript, Piscataway, NJ, USA). Twenty endotoxin-free vials were divided into five groups (negative control, positive control, saline, micro and nano-NiO groups), $0.1 \mathrm{ml}$ LAL solution was added into each tube, and then $0.1 \mathrm{ml}$ endotoxin-free water, Escherichia coli endotoxin standard, saline, $0.24 \mathrm{mg} / \mathrm{ml}$ micro or nano-NiO suspensions were transferred into the respective vials. Each vial was slowly turned upside down following incubation at $37^{\circ} \mathrm{C}$ for $1 \mathrm{~h}$. The gel remained intact when inverting the vial, and a positive reaction meant that the endotoxin levels were $>0.25 \mathrm{EU} / \mathrm{ml}$. By contrast, negative results showed that turbidity or viscosity increased.

Animals and treatment. Forty adult male Wistar rats (age, 6-8 weeks; weight, 200 $\pm 20 \mathrm{~g}$ ) were purchased from the Laboratory Animal Center of Lanzhou University (Lanzhou, China), housed in stainless steel cages in the laboratory with specific conditions ( $60 \%$ relative humidity, $20 \pm 2^{\circ} \mathrm{C}, 12$-h light/dark cycle). The animals were supplied with commercial diet and water ad libitum. All procedures on experimental animals complied with the ethics committee criteria of Lanzhou University, and were approved by the Care and Use Committee of Laboratory Animals of Lanzhou University (Lanzhou, Gansu, China).

Following acclimatization for one week, the 40 rats were randomized into five groups of 8 rats each: control group (administered with only physiological saline), $0.015 \mathrm{mg} / \mathrm{kg}$ body weight (b.w.) nano-NiO group, $0.06 \mathrm{mg} / \mathrm{kg}$ b.w. nano-NiO, $0.24 \mathrm{mg} / \mathrm{kg}$ b.w. nano-NiO, and $0.24 \mathrm{mg} / \mathrm{kg}$ b.w. micro-NiO group. These dosages of micro and nano-NiO were selected based on our previous studies $(9,10)$. Following anesthesia with inhaled diethyl ether, rats received either physiological saline, or micro or nano-NiO by intratracheal instillation twice a week for 6 consecutive weeks.

During the experimental period, body weight was measured prior to each intratracheal instillation. At the end of 6 the weeks of exposure, animals were sacrificed and the liver tissue was immediately excised and rinsed with ice-cold physiological saline. Then, the liver tissue was weighted in order to calculate the liver coefficient to body weight (wet weight in $\mathrm{mg} / 100 \mathrm{~g}$ of total body weight).

Histological examination. To explore if the liver was injured by the $\mathrm{NiO}$ particle administration in rats, liver tissues were fixed with $4 \%$ paraformaldehyde at room temperature for $48 \mathrm{~h}$, embedded in paraffin, cut into $5 \mu \mathrm{m}$ sections, then transferred onto slides. After removing the paraffin with xylene and dehydrating in graded ethanol, the sections were rehydrated and stained with hematoxylin and eosin. The slides were dehydrated with $95 \%$ and absolute ethanol, cleared in xylene and sealed by neutral gum. Five staining fields per sample were examined and photographed under a light microscope (BX53; Olympus Corporation, Tokyo, Japan).

Preparation of tissue homogenate. The right lobe of each liver tissue was chopped, diluted in physiological saline, and then grinded and centrifuged at $1,100 \mathrm{x}$ g for $10 \mathrm{~min}$ at $4^{\circ} \mathrm{C}$. The supernatant was collected, transferred into vials, and stored at $-80^{\circ} \mathrm{C}$ for further analysis. The protein concentration of 
Table I. Sequences of primers used for reverse transcription-quantitative polymerase chain reaction.

\begin{tabular}{|c|c|c|c|}
\hline Gene & Primer & Sequence $\left(5^{\prime}-3^{\prime}\right)$ & Product size (bp) \\
\hline$\beta$-actin & $\begin{array}{l}\text { Forward } \\
\text { Reverse }\end{array}$ & $\begin{array}{l}\text { CCAACCGTGAAAAGATGA } \\
\text { TACGACCAGAGGCATACAG }\end{array}$ & 102 \\
\hline HO-1 & $\begin{array}{l}\text { Forward } \\
\text { Reverse }\end{array}$ & $\begin{array}{l}\text { GAAGAGGAGATAGAGCGAAAC } \\
\text { CTGGTGTGTAAGGGATGG }\end{array}$ & 155 \\
\hline MT-1 & $\begin{array}{l}\text { Forward } \\
\text { Reverse }\end{array}$ & $\begin{array}{l}\text { АССТССТGCAAGAAGAGC } \\
\text { GCACCTTTGCAGACACAG }\end{array}$ & 184 \\
\hline
\end{tabular}

HO-1, heme oxygenase-1; MT-1, metallothionein-1.

the supernatant was measured with a bicinchoninic acid total protein quantification kit (Nanjing Jiancheng Bioengineering Institute, Nanjing, China).

Nitrative stress assay. The enzyme activities of total nitric oxide synthase (TNOS) and inducible nitric oxide synthase (iNOS) were assayed in $10 \%$ tissue homogenate by spectrophotometry at $530 \mathrm{~nm}$ wavelength, and the nitric oxide (NO) content was determined in $10 \%$ tissue homogenate at $550 \mathrm{~nm}$ wavelength, according to the instructions of the respective detection kits (Nanjing Jiancheng Bioengineering Institute).

Oxidative stress assay. The contents of hydroxyl radical $(\cdot \mathrm{OH})$, lipid peroxidation (LPO), catalase (CAT), glutathione peroxidase (GSH-Px), total superoxide dismutase (T-SOD) and total antioxidative capacity (T-AOC) were tested in $0.5,10,0.5,0.25$, 1 and $10 \%$ tissue homogenate respectively using commercial kits (Nanjing Jiancheng Bioengineering Institute) as per the manufacturer's instructions.

Reverse transcription-quantitative polymerase chain reaction (RT-qPCR). Approximately $95 \mathrm{mg}$ of tissue from the liver was resected from the experimental rats for RT-qPCR analysis of the mRNA expression levels of HO-1 and MT-1. According to the manufacturer's instructions, $1 \mathrm{ml}$ TRIzol reagent (Thermo Fisher Scientific, Inc., Waltham, MA, USA) was used to extract total RNA from the liver tissue. Total RNA was assessed using a NanoDrop 2000C spectrophotometer (Thermo Fisher Scientific, Inc.), and only samples of high quality, with A260/A280 ratios between 1.8 and 2.2, were selected for reverse transcription. cDNA synthesis was performed with the FastQuant RT kit (Tiangen Biotech Co., Ltd., Beijing, China). Then, qPCR was performed on an iQ5 real-time PCR detection system (Bio-Rad Laboratories, Inc. Hercules, CA, USA) using the qPCR SYBR-Green Mix (Tiangen Biotech Co., Ltd.). The specific operating conditions were as follows: $95^{\circ} \mathrm{C}$ for $15 \mathrm{~min}$ for initial denaturation, followed by 40 cycles of $95^{\circ} \mathrm{C}$ for $10 \mathrm{sec}, 60^{\circ} \mathrm{C}$ for $20 \mathrm{sec}$, and $72^{\circ} \mathrm{C}$ for $32 \mathrm{sec}$. Primer sequences are listed in Table I. The relative mRNA expression levels were calculated using the Pfaffl method (29).

Statistical analysis. Results were expressed as mean \pm standard deviation. Significance of differences between groups were analyzed with one-way analysis of variance followed by the least significant difference test, using the SPSS 21.0 software (IBM Corp., Armonk, NY, USA). P $<0.05$ was considered to indicate a statistically significant difference.

\section{Results}

Particle characterization. To avoid the $\mathrm{NiO}$ particles agglomeration caused by co-existing ions, van der Waals forces and static electricity, ultrasound and vortex oscillation were used to retain the particles in a scattered state (30). The physicochemical characteristics of $\mathrm{NiO}$ particles were presented in our previous study (9). The endotoxin levels were $<0.25 \mathrm{EU} / \mathrm{ml}$ in the micro and nano-NiO suspensions, which is regarded as a negative result.

Liver coefficient to body weight. Liver coefficient reflected the degree of liver injury caused by the $\mathrm{NiO}$ particles. As illustrated in Fig. 1, the liver wet weight and coefficient to body weight significantly increased following intratracheal instillation of $0.24 \mathrm{mg} / \mathrm{kg}$ nano-NiO, compared to the control and the $0.24 \mathrm{mg} / \mathrm{kg}$ micro-NiO groups $(\mathrm{P}<0.05)$.

Histopathology. The subchorionic liver toxicity induced by nano-NiO administration was evaluated in the experimental rats by observing liver tissue sections that were stained by hematoxylin and eosin (Fig. 2). The liver tissues of the control group exhibited a normal liver structure, with consecutive structure and clear outline. The distribution of hepatocytes was scattered and dissociated in the $0.015 \mathrm{mg} / \mathrm{kg}$ nano- $\mathrm{NiO}$ group. In the $0.06 \mathrm{mg} / \mathrm{kg}$ nano-NiO group, the loosely arranged hepatocytes appeared swollen, binucleated and infiltrated by lymphocytes. Cellular edema, hepatic sinus disappearance and binucleated hepatocytes, as well as cells mixed together with volume enlargement, were observed in the $0.24 \mathrm{mg} / \mathrm{kg}$ nano-NiO group. Finally, the $0.24 \mathrm{mg} / \mathrm{kg}$ micro-NiO group presented cellular edema, neutrophil and lymphocyte infiltration, binucleated hepatocytes, and sporadic spotty necrosis.

Nitrative stress assay. The indicators of nitrative stress (NO, TNOS and iNOS) were measured in order to evaluate the degree of liver toxicity induced by nano-NiO in rats. The changes of NO content, and the activities of TNOS and iNOS in the different experimental groups are depicted in Fig. 3. NO content and TNOS and iNOS activities were significantly increased in the $0.24 \mathrm{mg} / \mathrm{kg}$ nano- $\mathrm{NiO}$ group compared with the control group $(\mathrm{P}<0.05)$. In addition, significant differences 
A

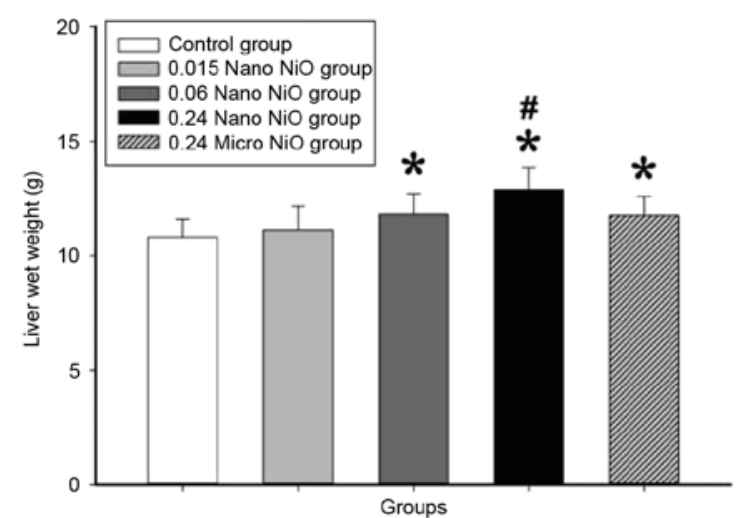

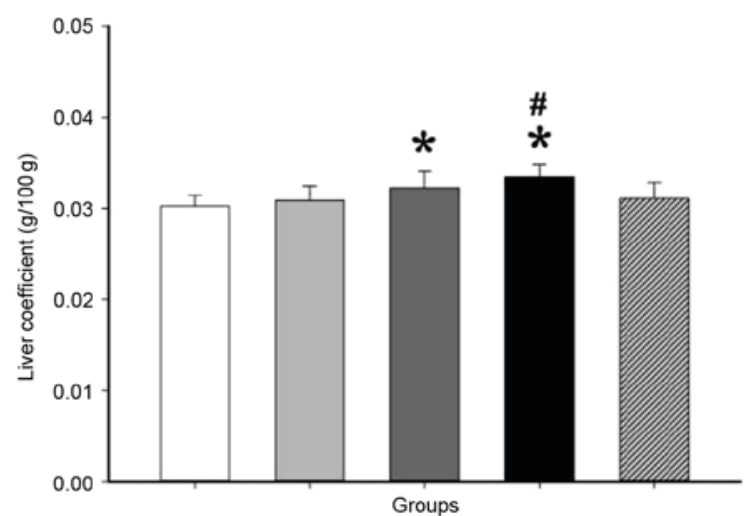

Figure 1. Effects of $\mathrm{NiO}$ particles on liver wet weight and coefficient to body weight in rats. (A) Liver wet weight and (B) liver coefficient to body weight were measured in the control (saline) and $\mathrm{NiO}$ particle-administered groups. Data are expressed as mean \pm standard deviation $(\mathrm{n}=8)$. ${ }^{*} \mathrm{P}<0.05$ vs. control; ${ }^{*} \mathrm{P}<0.05$ vs. $0.24 \mathrm{mg} / \mathrm{kg}$ micro-NiO group. $\mathrm{NiO}$, nickel oxide; Nano, nanoparticles; Micro, microparticles.
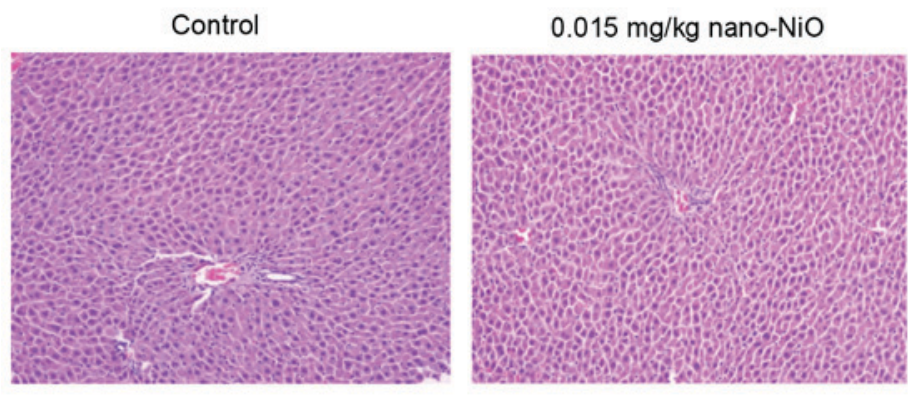

$0.06 \mathrm{mg} / \mathrm{kg}$ nano-NiO

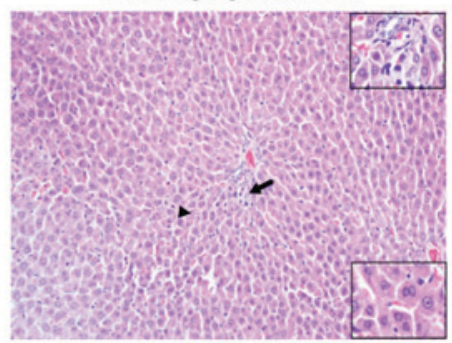

$0.24 \mathrm{mg} / \mathrm{kg}$ nano-NiO

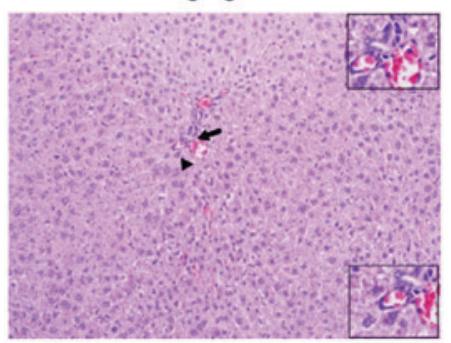

$0.24 \mathrm{mg} / \mathrm{kg}$ micro-NiO

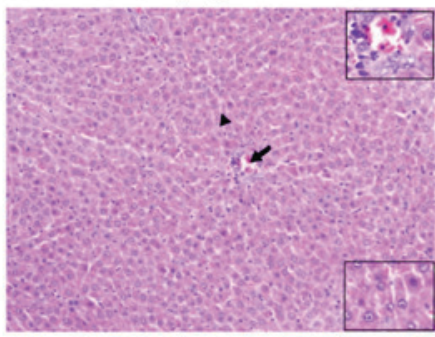

Figure 2. Photomicrographs of liver tissue sections stained with hematoxylin and eosin from control (saline) and $\mathrm{NiO}$ particle-administered groups ( $\mathrm{n}=5$ ). Magnification, x200. Insets illustrate portions of the photographs in higher magnification (magnification, x400). Arrows denote neutrophil infiltration and arrowheads denote binucleated hepatocytes. NiO, nickel oxide; Nano, nanoparticles; Micro, microparticles.

A

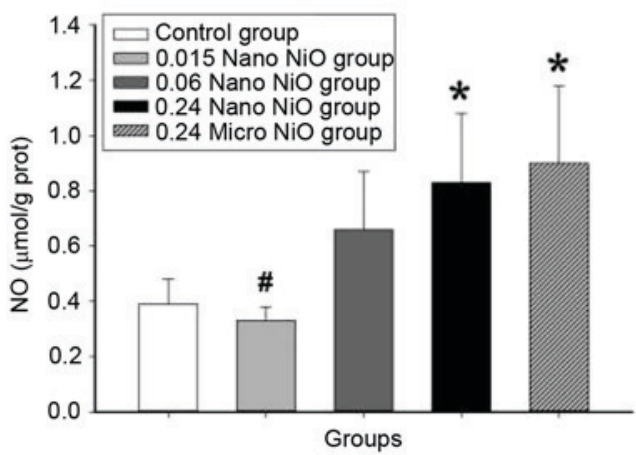

B

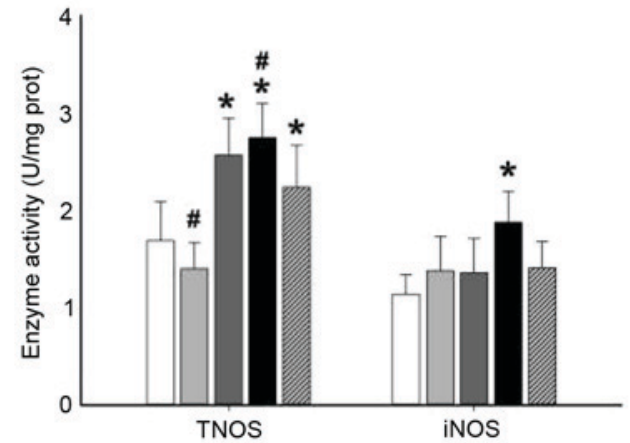

Figure 3. Indicators of nitrative stress in rat liver tissues following administration of NiO particles. (A) The content of NO and (B) the activities of TNOS and iNOS were measured in the control (saline) and $\mathrm{NiO}$ particle-administered groups. Data are expressed as mean \pm standard deviation $(\mathrm{n}=8)$. ${ }^{*} \mathrm{P}<0.05 \mathrm{vs}$. control; ${ }^{\#} \mathrm{P}<0.05$ vs. $0.24 \mathrm{mg} / \mathrm{kg}$ micro-NiO group. NiO, nickel oxide; NO, nitric oxide; TNOS, total nitric oxide synthase; iNOS, inducible nitric oxide synthase; Nano, nanoparticles; Micro, microparticles. 


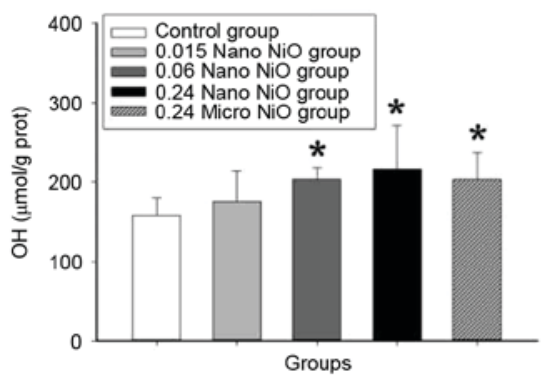

D

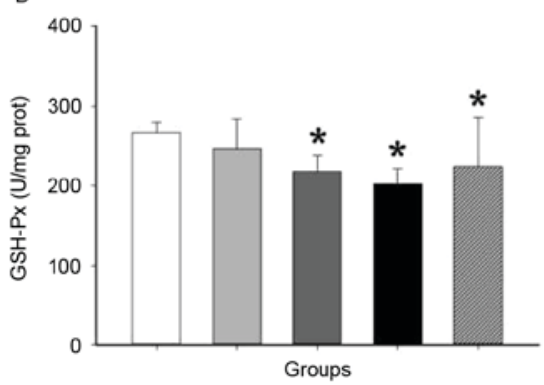

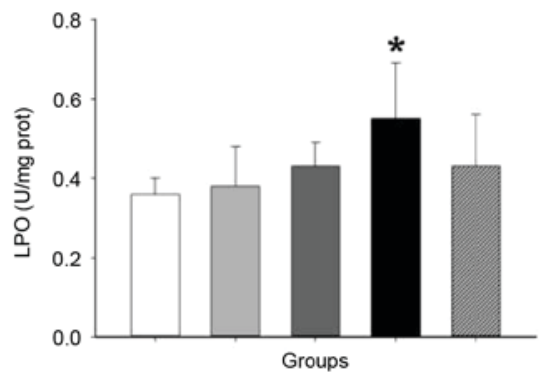

$\mathrm{E}$

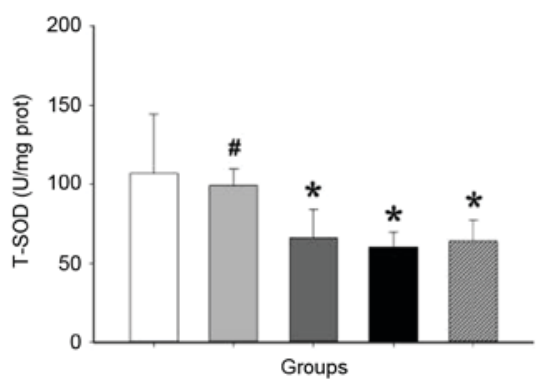

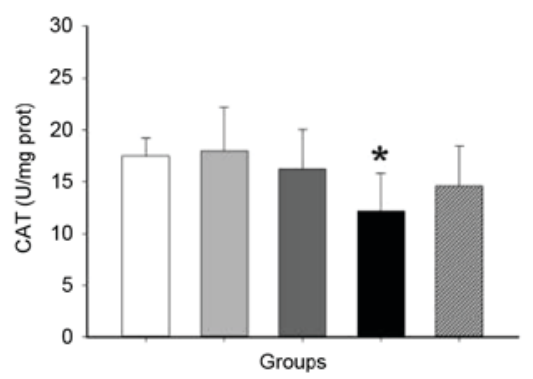

$\mathrm{F}$

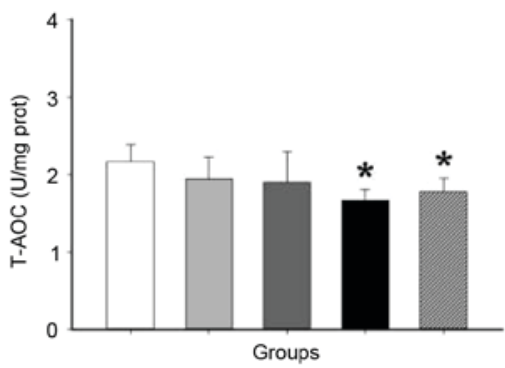

Figure 4. Indicators of oxidative stress in rat liver tissues following administration of NiO particles. Levels of (A) ·OH, (B) LPO, (C) CAT, (D) GSH-Px, (E) T-SOD and (F) T-AOC were measured in the control (saline) and NiO particle-administered groups. Data are expressed as mean \pm standard deviation (n=8), ${ }^{*} \mathrm{P}<0.05$ vs. control; " $\mathrm{P}<0.05$ vs. $0.24 \mathrm{mg} / \mathrm{kg}$ micro-NiO group. $\mathrm{NiO}$, nickel oxide; $\cdot \mathrm{OH}$, hydroxyl radical; LPO, lipid peroxidation; CAT, catalase; GSH-Px, glutathione peroxidase; T-SOD, total superoxide dismutas; T-AOC, total antioxidative capacity; Nano, nanoparticles; Micro, microparticles.

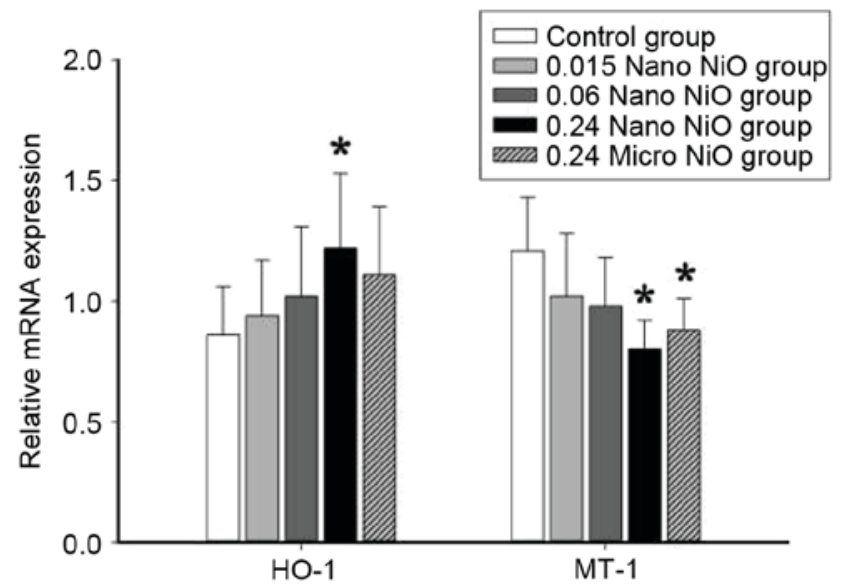

Figure 5. Relative mRNA expression levels of HO-1 and MT-1 in rat liver tissues following administration of $\mathrm{NiO}$ particles. Data are expressed as mean \pm standard deviation $(\mathrm{n}=8)$. ${ }^{\mathrm{P}} \mathrm{P}<0.05$ vs. control. HO-1, heme oxygenase-1; MT-1, metallothionein-1; NiO, nickel oxide; Nano, nanoparticles; Micro, microparticles.

in the NO content and TNOS activity were observed also in the micro- $\mathrm{NiO}$ and the $0.015 \mathrm{mg} / \mathrm{kg}$ nano- $\mathrm{NiO}$ groups compared with the control group $(\mathrm{P}<0.05)$.

Oxidative stress assay. Oxidative stress indicators were examined in the livers of the experimental groups in order to explore the mechanism of liver injury induced by nano-NiO. As demonstrated in Fig. 4, the contents of $\cdot \mathrm{OH}$ and LPO increased in the $0.24 \mathrm{mg} / \mathrm{kg}$ nano-NiO group compared with the control group $(\mathrm{P}<0.05)$. In addition, the activities of the antioxidant enzymes CAT, GSH-Px, T-SOD and T-AOC were significantly decreased in the liver tissues of the $0.24 \mathrm{mg} / \mathrm{kg}$ nano-NiO group compared with the control group $(\mathrm{P}<0.05)$.
Analysis of HO-1 and MT-1 mRNA expression. The relative mRNA expression levels of HO-1 and MT-1 were detected in the liver tissues in order to examine the effect of nano-NiO administration in oxidative stress induction. As demonstrated in Fig. 5, the relative HO-1 mRNA levels were significantly elevated in the $0.24 \mathrm{mg} / \mathrm{kg}$ nano- $\mathrm{NiO}$ group compared with the control group $(\mathrm{P}<0.05)$. By contrast, the relative MT-1 mRNA levels were reduced in the $0.24 \mathrm{mg} / \mathrm{kg}$ nano-NiO group compared with the control group $(\mathrm{P}<0.05$; Fig. 5).

\section{Discussion}

Nano-NiO particles are widely used in production industries, however, important aspects of its toxicology, such as the organism-level toxicokinetic and dose-response relationships, can only be addressed through experiments on a whole mammalian organism (28). The liver is the main organ responsible for metabolism of both endogenous and exogenous compounds, therefore it is one of the main target organs for the toxic action of xenobiotics or their reactive metabolites (31). In addition, the respiratory system is the most common route of exposure to particulate matters, especially nanoparticles (32), which enter the circulatory system via the gastrointestinal tract and then get distributed in the liver. To date, few studies on liver toxicity induced by nano-NiO exist and the mechanism in animal models remains unclear. For all these reasons, the present study generated a rat liver injury model induced by nano-NiO administration via intratracheal instillation and explored its potential mechanisms.

In the present study, an increase in liver wet weight and coefficient to body weight were observed following nano-NiO administration, suggesting liver damage induced by nano-NiO. Observation of liver pathological changes revealed cellular 
edema, hepatic sinus disappearance, binucleated hepatocytes, and cells mixed together with volume enlargement. The results suggested that the present animal model of liver injury was successfully generated by intratracheal instillation of nano-NiO twice a week for 6 consecutive weeks in rats.

The production of radical species, such as reactive nitrogen species, has been proposed as an early event and indicator of hepatotoxicity (33). Nitrative stress leads to the activation of iNOS and oxidative metabolism of NO (34). NO is a diffusible molecule that mediates a variety of cellular physiological and pathophysiological responses. Excessive production of NO produces the formation of reactive nitrogen species, such as peroxynitrite and nitrogen dioxide (35). Exposure to toxic levels of ozone causes the upregulation of iNOS in lung tissue (36). The increased nitrite and nitrate levels in fish livers may be due to the enhanced activity of TNOS and hence overproduction of $\mathrm{NO}$ (37). In the present study, an increase of NO, TNOS and iNOS were observed in liver tissue, which implied that nano-NiO-induced nitrative stress could be involved in liver toxicity.

Reactive nitrogen species as free radicals lead to oxidative stress (38). At a preliminary level, it is hypothesized that oxidative stress induced by nanoparticles may be a major mechanism of their toxicity and is often a focal point of studies (39). Oxidative stress could disturb antioxidant defense mechanisms of the liver by affecting antioxidant-related enzyme activities (40). When the body antioxidant capacity can no longer protect the cell from oxidative damage, free radicals accumulate and exert detrimental effects, including LPO and protein oxidation (41). LPO, a process contributing to the development of oxygen radical-related damages, is one of the major causes of cell membranes damage (42). $\cdot \mathrm{OH}$ is the most reactive of all reduced forms of dioxygen studied in recent years, along with lipid peroxidation (43). The present study demonstrated that levels of $\cdot \mathrm{OH}$ and LPO were increased following nano-NiO particle administration, implying raised oxidation levels.

Antioxidant enzymes, including SOD, CAT and GSH-Px, prevent the oxidation-induced damages (43). SOD promotes the production of $\mathrm{O}_{2}$ and $\mathrm{H}_{2} \mathrm{O}_{2}$ from $\mathrm{O}_{2-}$, which in turn are converted to water by CAT, thus avoiding the formation of $\cdot \mathrm{OH}$. CAT is one of the crucial antioxidant enzymes that protects the body from oxidative stress. T-AOC serves a crucial role in the antioxidant defense system. Nickel sulfate leads to decreasing activities of enzymatic antioxidants, including SOD, CAT and GSH-Px, in rat livers (17). Sidhu et al (44) reported that sulfate administration causes a significant inhibition in GSH content and SOD activity in liver tissue (44). The present study demonstrated that the activities of CAT, GSH-Px, SOD and T-AOC were decreased in liver tissues following nano-NiO particle administration, indicating that the antioxidant system failed to maintain cellular redox equilibrium.

HO-1 and MT-1 genes are rapidly upregulated by proinflammatory cytokines or oxidative stress, as a protection mechanism against cellular stress in the liver (45). HO-1 is widely used as a sensitive stress response marker in oxidative damage induced by xenobiotics (46). MT-1 ameliorates the effects of oxidative stress by scavenging free radicals or preventing their formation (47). Horie et al (48) reported that the relative HO-1 gene levels increased following intratracheal instillation of nano-NiO and nickel chloride in rat bronchoalveolar lavage fluid (48).
Increased mRNA expression levels of MT-1 were observed in the lung and liver following nickel sulfate exposure via a single intratracheal instillation (49). The present study demonstrated that decreased MT-1 and increased HO-1 gene expression in liver tissue, suggesting a deficient antioxidant and detoxification capacity induced by nano- $\mathrm{NiO}$ administration in rats.

It has been hypothesized that smaller particle size is associated with higher specific surface area and reactivity, thus nanoparticles may release more ions for intracellular uptake and mobilization, resulting in higher bioavailability than microparticles (50). In order to explore the size impact of the particles, liver toxicity was examined following administration of both nano and micro-NiO, and the present results indicated that nano-NiO produced a stronger liver toxicity than micro-NiO particles.

In summary, nano-NiO administration via intratracheal instillation led to the imbalance of oxidation and antioxidants, as well as the occurrence of nitrative stress in rats. The present study indicated that the liver toxicity may be associated with nitrative stress, oxidative stress and abnormal expression of HO-1 and MT-1 mRNA induced by nano-NiO. However, the exact mechanism of liver toxicity induced by nano-NiO remains unclear and further studies in vitro and in vivo will be required. The current findings may provide helpful evidence for the safety assessment of nano-NiO administration.

\section{Acknowledgements}

The present study was supported by the Fundamental Research Funds for the Central Universities of China (grant no. lzujbky-2016-205) and the National Undergraduate Training Programs for Innovation and Entrepreneurship (grant no. 201610730162).

\section{References}

1. Gajewicz A, Rasulev B, Dinadayalane TC, Urbaszek P, Puzyn T, Leszczynska D and Leszczynski J: Advancing risk assessment of engineered nanomaterials: Application of computational approaches. Adv Drug Deliv Rev 64: 1663-1693, 2012.

2. He X, Aker WG, Fu PP and Hwang HM: Toxicity of engineered metal oxide nanomaterials mediated by nano-bio-eco-interactions: A review and perspective. Environ Sci: Nano 2: 564-582, 2015.

3. Andersen NI, Serov A and Atanassov P: Metal oxides/CNT nano-composite catalysts for oxygen reduction/oxygen evolution in alkaline media. Appl Catal B: Environ 163: 623-627, 2015.

4. Liu RC, Liang F, Zhou W, Yang Y and Zhu Z: Calcium-doped lanthanum nickelate layered perovskite and nickel oxide nano-hybrid for highly efficient water oxidation. Nano Energy 12: 115-122, 2015.

5. Zanni E, Palma SD, Chandraiahgari CR, Bellis GD, Cialfi S, Talora C, Palleschi C, Sarto MS, Uccelletti D and Mancini P: In vitro toxicity studies of zinc oxide nano- and microrods on mammalian cells: A comparative analysis. Mater Lett 179: 90-94, 2016.

6. Ogami A, Morimoto Y, Myojo T, Oyabu T, Murakami M, Todoroki M, Nishi K, Kadoya C, Yamamoto M and Tanaka I: Pathological features of different sizes of nickel oxide following intratracheal instillation in rats. Inhal Toxicol 21: 812-818, 2009.

7. Horie M, Fukui H, Nishio K, Endoh S, Kato H, Fujita K, Miyauchi A, Nakamura A, Shichiri M, Ishida N, et al: Evaluation of acute oxidative stress induced by $\mathrm{NiO}$ nanoparticles in vivo and in vitro. J Occup Health 53: 64-74, 2011.

8. Duan WX, He MD, Mao L, Qian FH, Li YM, Pi HF, Liu C, Chen $\mathrm{CH}$, Lu YH, Cao ZW, et al: NiO nanoparticles induce apoptosis through repressing SIRT1 in human bronchial epithelial cells. Toxicol Appl Pharmacol 286: 80-91, 2015. 
9. Zhu A, Chang X, Sun Y,Zou L, Li S, Sun Y, Li S, Sun Y, Zhou H and Li J: Role of oxidative stress and inflammatory response in subchronic pulmonary toxicity induced by nano nickel oxide in rats. J Nanosci Nanotechno 17: 1753-1761, 2017.

10. Chang X, Zhu A, Liu F, Zou L, Su L, Li S and Sun Y: Role of $\mathrm{NF}-\kappa \mathrm{B}$ activation and Th1/Th2 imbalance in pulmonary toxicity induced by nano-NiO. Environ Toxicol 32: 1354-1362, 2017.

11. Veranth JM, Kaser EG, Veranth MM, Koch M and Yost GS Cytokine responses of human lung cells (BEAS-2B) treated with micron-sized and nanoparticles of metal oxides compared to soil dusts. Part Fibre Toxicol 4: 2, 2007.

12. Karlsson HL, Gliga AR, Calleja FM, Goncalves CS, Wallinder IO, Vrieling H, Fadeel B and Hendriks G: Mechanism-based genotoxicity screening of metal oxide nanoparticles using the ToxTracker panel of reporter cell lines. Part Fibre Toxicol 11: 41, 2014.

13. Horie M, Nishio K, Kato H, Endoh S, Fujita K, Nakamura A Miyauchi A, Kinugasa S, Hagihara Y, Yoshida Y and Iwahashi H: The expression of inflammatory cytokine and heme oxygenasegenes in $\mathrm{THP}_{-1}$ cells exposed to metal oxide nanoparticles. J Nano Res 30: 116-127, 2015.

14. Lu S, Zhang W, Zhang R, Liu P, Wang Q, Shang Y, Wu M, Donaldson $\mathrm{K}$ and Wang Q: Comparison of cellular toxicity caused by ambient ultrafine particles and engineered metal oxide nanoparticles. Part Fibre Toxicol 12: 5, 2015.

15. Ates M, Demir V, Arslan Z, Camas M and Celik F: Toxicity of engineered nickel oxide and cobalt oxide nanoparticles to artemia salina in seawater. Water Air Soil Pollut 227: pii: 70, 2016.

16. Stine JG and Lewis JH: Current and future directions in the treatment and prevention of drug-induced liver injury: A systematic review. Expert Rev Gastroenterol Hepatol 10: 517-536, 2016.

17. Pari L and Prasath A: Efficacy of caffeic acid in preventing nickel induced oxidative damage in liver of rats. Chem Biol Interact 173: 77-83, 2008

18. Liu CM, Ma JQ, Liu SS, Feng ZJ and Wang AM: Puerarin protects mouse liver against nickel-induced oxidative stress and inflammation associated with the TLR4/p38/CREB pathway. Chem Biol Interact 243: 29-34, 2016.

19. Zheng GH,Liu CM,Sun JM,Feng ZJ and Cheng C: Nickel-induced oxidative stress and apoptosis in carassius auratus liver by JNK pathway. Aquat Toxicol 147: 105-111, 2014.

20. Permenter MG, Lewis JA and Jackson DA: Exposure to nickel, chromium, or cadmium causes distinct changes in the gene expression patterns of a rat liver derived cell line. PLoS One 6 : e27730, 2011.

21. AhmadJ,AlhadlaqHA,SiddiquiMA,SaquibQ,Al-KhedhairyAA, Musarrat J and Ahamed M: Concentration-dependent induction of reactive oxygen species, cell cycle arrest and apoptosis in human liver cells after nickel nanoparticles exposure. Environ Toxicol 30: 137-148, 2015.

22. Knight JA, Plowman MR, Hopfer SM and Sunderman FW Jr: Pathological reactions in lung, liver, thymus, and spleen of rats after subacute parenteral administration of nickel sulfate. Ann Clin Lab Sci 21: 275-283, 1991

23. Sidhu P, Garg ML, Morgenstern P, Vogt J, Butz T and Dhawan DK: Role of zinc in regulating the levels of hepatic elements following nickel toxicity in rats. Biol Trace Elem Res 102: 161-172, 2004.

24. Ahamed M, Ali D, Alhadlaq HA and Akhtar MJ: Nickel oxide nanoparticles exert cytotoxicity via oxidative stress and induce apoptotic response in human liver cells (HepG2). Chemosphere 93: 2514-2522, 2013.

25. AhmadJ,AlhadlaqHA,SiddiquiMA,SaquibQ,Al-KhedhairyAA, Musarrat $\mathrm{J}$ and Ahamed $\mathrm{M}$ : Concentration-dependent induction of reactive oxygen species, cell cycle arrest and apoptosis in human liver cells after nickel nanoparticles exposure. Environ Toxicol 30: 137-148, 2015.

26. Magaye RR, Yue X, Zou B, Shi H, Yu H, Liu K, Lin X, Xu J, Yang C, Wu A and Zhao J: Acute toxicity of nickel nanoparticles in rats after intravenous injection. Int J Nanomedicine 9: 1393-1402, 2014

27. Ahamed M, Akhtar MJ, Alhadlaq HA, Khan MA and Alrokayan SA: Comparative cytotoxic response of nickel ferrite nanoparticles in human liver HepG2 and breast MFC-7 cancer cells. Chemosphere 135: 278-288, 2015.

28. Katsnelson BA, Minigaliyeva IA, Panov VG, Privalova LI, Varaksin AN, Gurvich VB, Sutunkova MP, Shur VY, Shishkina EV, Valamina IE and Makeyev OH: Some patterns of metallic nanoparticles' combined subchronic toxicity as exemplified by a combination of nickel and manganese oxide nanoparticles. Food Chem Toxicol 86: 351-364, 2015.
29. Pfaffl MW: A new mathematical model for relative quantification in real-time RT-PCR. Nucleic Acids Res 29: e45, 2001.

30. Morimoto Y, Ogami A, Todoroki M, Yamamoto M, Murakami M, Hirohashi M, Oyabu T, Myojo T, Nishi K, Kadoya C, et al: Expression of inflammation-related cytokines following intratracheal instillation of nickel oxide nanoparticles. Nanotoxicology 4 : $161-176,2010$

31. Cao L, Du J, Ding W, Jia R, Liu Y, Xu P, Teraoka H and Yin G: Hepatoprotective and antioxidant effects of dietary Angelica sinensis extract against carbon tetrachloride-induced hepatic injury in Jian Carp (Cyprinus carpio var. Jian). Aquac Res 47: 1852-1863, 2016.

32. Magaye R, Gu Y, Wang Y, Su H, Zhou Q, Mao G, Shi H, Yue X, Zou B, Xu J and Zhao J: In vitro and in vivo evaluation of the toxicities induced by metallic nickel nano and fine particles. J Mol Histol 47: 273-286, 2016.

33. Shuhendler AJ, Pu K, Cui L, Uetrecht JP and Rao J: Real-time imaging of oxidative and nitrosative stress in the liver of live animals for drug-toxicity testing. Nat Biotechnol 32: 373-380, 2014

34. Li X, Li H, Lu N, Feng Y, Huang Y and Gao Z: Iron increases liver injury through oxidative/nitrative stress in diabetic rats: Involvement of nitrotyrosination of glucokinase. Biochimie 94: 2620-2627, 2012.

35. Sugiura $\mathrm{H}$ and Ichinose $\mathrm{M}$ : Oxidative and nitrative stress in bronchial asthma. Antioxid Redox Signal 10: 785-797, 2008.

36. Roberts RA, Laskin DL, Smith CV, Robertson FM, Allen EM, Doorn JA and Slikker W: Nitrative and oxidative stress in toxicology and disease. Toxicol Sci 112: 4-16, 2009.

37. Padmini E, Vijaya Geetha B and Usha Rani M: Pollution induced nitrative stress and heat shock protein 70 overexpression in fish liver mitochondria. Sci Total Environ 407: 1307-1317, 2009.

38. Bian K and Murad F: Diversity of endotoxin-induced nitrotyrosine formation in macrophage-endothelium-rich organs. Free Radic Biol Med 31: 421-429, 2001

39. Muñoz A and Costa M: Elucidating the mechanisms of nickel compound uptake: A review of particulate and nano-nickel endocytosis and toxicity. Toxicol Appl Pharmacol 260: 1-16, 2012.

40. Cao W, Xiao L, Liu G, Fang T, Wu X, Jia G, Zhao H, Chen X, Wu C, Cai J and Wang J: Dietary arginine and $\mathrm{N}$-carbamylglutamate supplementation enhances the antioxidant statuses of the liver and plasma against oxidative stress in rats. Food Funct 7: 2303-2311, 2016.

41. Zhou BH, Zhao J, Liu J, Zhang JL, Li J and Wang HW: Fluoride-induced oxidative stress is involved in the morphological damage and dysfunction of liver in female mice. Chemosphere 139: 504-511, 2015.

42. Koc M, Taysi S, Buyukokuroglu ME and Bakan N: Melatonin protects rat liver against irradiation-induced oxidative injury. J Radiat Res 44: 211-215, 2003.

43. Bai K, Xu W, Zhang J, Kou T, Niu Y, Wan X, Zhang L, Wang C and Wang T: Assessment of free radical scavenging activity of dimethylglycine sodium salt and its role in providing protection against lipopolysaccharide-induced oxidative stress in mice. PLoS One 11: e0155393, 2016.

44. Sidhu P, Garg ML and Dhawan DK: Protective role of zinc in nickel induced hepatotoxicity in rats. Chem Biol Interact 150: 199-209, 2004

45. Abrahám S, Hermesz E, Szabó A, Ferencz A, Jancsó Z, Duda E, Abrahám M, Lázár G and Lázár G Jr: Effects of Kupffer cell blockade on the hepatic expression of metallothionein and heme oxygenase genes in endotoxemic rats with obstructive jaundice. Life Sci 90: 140-146, 2012.

46. Gutierrez ER, Kamens RM, Tolocka M, Sexton K and Jaspers I: A comparison of three dispersion media on the physicochemical and toxicological behavior of $\mathrm{TiO} 2$ and $\mathrm{NiO}$ nanoparticles. Chem Biol Interact 236: 74-81, 2015.

47. Takano H, Inoue K, Yanagisawa R, Sato M, Shimada A, Morita T, Sawada M, Nakamura K, Sanbongi C and Yoshikawa T: Protective role of metallothionein in acute lung injury induced by bacterial endotoxin. Thorax 59: 1057-1062, 2004 .

48. Horie M, Fukui H, Endoh S, Maru J, Miyauchi A, Shichiri M, Fujita K, Niki E, Hagihara Y, Yoshida Y, et al: Comparison of acute oxidative stress on rat lung induced by nano and fine-scale, soluble and insoluble metal oxide particles: $\mathrm{NiO}$ and $\mathrm{TiO} 2$. Inhal Toxicol 24: 391-400, 2012.

49. Wallenborn JG, Schladweiler MJ, Richards JH and Kodavanti UP: Differential pulmonary and cardiac effects of pulmonary exposure to a panel of particulate matter-associated metals. Toxicol Appl Pharmacol 241: 71-80, 2009.

50. Pietroiusti A: Health implication of engineered nanomaterials. Nanoscale 4: 1231-1247, 2012. 